\title{
Saliva Substitutes in Combination with Highly Concentrated Fluorides and Brushing: In vitro Effects on Enamel Subsurface Lesions
}

\author{
P. Tschoppe ${ }^{a} \quad$ A. Siegel ${ }^{a} \quad$ H. Meyer-Lueckel ${ }^{b}$ \\ a Department of Operative Dentistry and Periodontology, University School of Dental Medicine, CharitéCentrum 3, \\ Charité - Universitätsmedizin Berlin, Berlin, and ${ }^{b}$ Clinic for Conservative Dentistry and Periodontology, School of Dental \\ Medicine, Christian-Albrechts-Universität zu Kiel, Kiel, Germany
}

\section{Key Words}

Demineralisation $\cdot$ Enamel $\cdot$ Fluoride gel .

Microradiography $\cdot$ Octacalcium phosphate $\cdot$

Remineralisation · Saliva substitute · Subsurface lesion •

Toothpaste

\begin{abstract}
Hyposalivation is often associated with high caries activity, in particular in patients undergoing irradiation in the head/ neck area. Besides the use of saliva substitutes to relieve the oral symptoms, daily application of fluoride gels or toothpaste $\left(5,000 \mu \mathrm{g} \mathrm{F}^{-} / \mathrm{g}\right)$ is recommended for caries prevention. The aim of this study was to evaluate potentially remineralising effects of these fluoride agents in combination with saliva substitutes on enamel subsurface lesions. Demineralised bovine specimens were either stored in mineral water [control; saturation with respect to octacalcium phosphate $\left(\mathrm{S}_{\mathrm{OCP}}\right)$ : 0.8 , a demineralising saliva substitute (Glandosane; $\mathrm{S}_{\text {OCP: }}$ 0.3 ) or in a modified (with respect to $S_{O C P}$ ) saliva substitute [Saliva natura (SN); SOCP: 1.9] for 5 weeks $\left(37^{\circ} \mathrm{C}\right)$. The following treatments were applied twice daily (11-13/group): no treatment (0), ProSchmelz fluoride gel (PS; $10 \mathrm{~min}$ application), Duraphat toothpaste (DP; $10 \mathrm{~s}$; brushing with toothpaste/ storage solution slurry), combination of DP+PS. Mineral pa-
\end{abstract}

rameters before/after storage were evaluated from microradiographs. Storage in Glandosane led to significant demineralisation ( $p<0.05$; paired $t$ test), whereas additional use of fluoride agents neutralised the demineralising effect $(p>$ $0.05)$. Storage in water alone resulted in no changes in mineral parameters $(p>0.05)$, whereas in combination with fluorides remineralisation could be shown $(p<0.05)$. For $S N$ alone, remineralisation was observed $(p<0.05)$, but no additional beneficial effects of fluorides were detected. Under the conditions chosen, the fluoride agents reduce the demineralising effects of Glandosane and promote the remineralisation of specimens stored in water. Remineralising effects of SN could not be enhanced by the fluorides.

Copyright $\odot 2010$ S. Karger AG, Basel

Patients suffering from hyposalivation arising from irradiation in the head and neck area frequently experience high caries activity [Atkinson et al., 2005; Kielbassa et al., 2006]. For caries prevention, the daily application of fluoride agents in combination with meticulous oral hygiene and the careful control of diet are recommended. Saliva substitutes are most frequently applied to relieve the sensation of dry mouth [Epstein et al., 1996; Vissink et al., 2003].

\section{KARGER}

Fax +41613061234 E-Mail karger@karger.ch www.karger.com
(C) 2010 S. Karger AG, Basel

0008-6568/10/0446-0571\$26.00/0

Accessible online at:

www.karger.com/cre
Dr. Peter Tschoppe

Abteilung für Zahnerhaltungskunde und Parodontologie, CharitéCentrum 3 für

Zahn-, Mund- und Kieferheilkunde, Charité - Universitätsmedizin Berlin

Assmannshauser Strasse 4-6, DE-14197 Berlin (Germany)

Tel. +4930450562 327, Fax +49 30450562 924, E-Mail peter.tschoppe@ charite.de 
Some commercially available saliva substitutes have demonstrated neutral or remineralising effects, and others have been shown to substantially demineralise enamel and dentin [Joyston-Bechal and Kidd, 1987; Smith et al., 2001; Meyer-Lueckel et al., 2002]. To increase remineralising capacities, fluoride, calcium and phosphate have been added to saliva substitutes, leading to solutions that are supersaturated with respect to the relevant calcium phosphates, such as octacalcium phosphate (OCP) and hydroxyapatite (HA). As a result of the use of these experimental saliva substitutes, remineralisation has been observed in vitro [Tschoppe et al., 2009b; MeyerLueckel et al., 2010].

For caries prevention, in addition to the regular use of fluoride toothpaste, highly fluoridated products such as gels are commonly recommended for irradiated patients [Nieuw Amerongen and Veerman, 2003]. Highly concentrated fluoride toothpaste seems to have a beneficial effect on the rehardening of root caries [Lynch and Baysan, 2001]. However, patients often demonstrate poor compliance with these regimens [Horiot et al., 1983; Epstein et al., 1996]. Preferably, a remineralising saliva substitute could manage both outcomes (dental caries and hyposalivation) while avoiding the additional use of highly concentrated fluoride agents (e.g. gels or special toothpastes).

The aim of this in vitro study was to evaluate the effects of daily applications of a fluoride gel and/or brushing with toothpaste (with a high fluoride content of 5,000 $\mathrm{g} \mathrm{F}^{-} / \mathrm{g}$ ) on demineralised bovine enamel in combination with 2 saliva substitutes using a remineralisation model. Because a commercially available, potentially demineralising saliva substitute (Glandosane) is still commonly used, this product was compared with a potentially remineralising solution [modified in saturation with respect to the relevant calcium phosphates (Saliva natura, SN; Medac, Hamburg, Germany)]. Mineral water was used as a control. We hypothesised that the additional use of a fluoride agent in combination with the demineralising saliva substitute (Glandosane) would result in a significantly less pronounced demineralisation effect and that using the remineralising saliva substitute (modified SN) would result in significantly enhanced remineralisation.

\section{Materials and Methods}

\section{Specimen Preparation}

Eighty recently extracted permanent bovine central incisors were used. From each crown, 2 specimens $\left(6 \times 4 \times 4 \mathrm{~mm}^{3}\right)$ from the labial aspect were prepared under running tap water using a diamond-coated band saw (Exakt 300cl; Exakt Apparatebau,
Norderstedt, Germany). Subsequently, the 160 enamel specimens were embedded in epoxy resin (Technovit 4071; Heraeus Kulzer, Wehrheim, Germany), and the natural surface was kept free from resin. The specimens were ground flat and hand-polished to 4,000 grit (silicon carbide; Struers, Copenhagen, Denmark), thereby removing the outer parts of the enamel (approx. $200 \mu \mathrm{m}$ ).

One quarter of each specimen's surface was covered with an acid-resistant nail varnish (Lycra Flex + Silk; Astor, Paris, France) to serve as a sound enamel control. Artificial lesions were prepared by immersion in 5 litres of a solution containing $6 \mu \mathrm{mol} / \mathrm{l}$ methylhydroxydiphosphonate, $3 \mathrm{mmol} / 1 \mathrm{CaCl}_{2} \cdot 2 \mathrm{H}_{2} \mathrm{O}, 3 \mathrm{mmol} / \mathrm{l}$ $\mathrm{KH}_{2} \mathrm{PO}_{4}$ and $50 \mathrm{mmol} / 1 \mathrm{CH}_{3} \mathrm{COOH}$ (Merck, Darmstadt, Germany) at $\mathrm{pH} 4.95$ in an incubator $\left(37^{\circ} \mathrm{C}\right.$; BR 6000; Heraeus Kulzer) for 15 days. The $\mathrm{pH}$ value was monitored daily ( $\mathrm{pH}$ electrode $\mathrm{GE}$ 100 BNC connected to pH meter GMH 3510; Greisinger, Regenstauf, Germany), and slight elevations were corrected with hydrochloric acid to maintain the $\mathrm{pH}$ between 4.92 and 4.98 during the demineralisation period. Standard buffer solutions (SigmaAldrich, Steinheim, Germany) with nominal $\mathrm{pH}$ values of 4.0 and $7.0 \pm 0.01$ units were used to calibrate the $\mathrm{pH}$ meter. After the demineralisation period, 4 specimens were evaluated using transversal microradiography to control the outcome of the demineralisation process (i.e. the creation of subsurface lesions).

\section{Preparation of Experimental Solutions}

For aqueous solutions, the degrees of saturation with respect to the caries-relevant compounds (e.g. dicalcium phosphate dihydrate, OCP, HA, calcium fluoride and fluoroapatite) can be calculated if the $\mathrm{pH}$ and the concentrations of certain ions are known (table 1). Furthermore, using the software developed by Shellis [1988], the ionic strength has been included in the calculation of the degrees of saturation. The calcium-to-phosphate ratio of the modified SN (polysaccharide-based) was determined to be 1:1.6. The natural calcium and phosphate of the unmodified SN solution [Tschoppe et al., 2009a] and the further addition of calcium (as $\mathrm{CaCl}_{2} \cdot 2 \mathrm{H}_{2} \mathrm{O}$ ) and phosphate $\left(\right.$ as $\mathrm{K}_{2} \mathrm{HPO}_{4} / \mathrm{KH}_{2} \mathrm{PO}_{4}$ ) resulted in a supersaturated solution with respect to the relevant calcium phosphates at the buffered $\mathrm{pH}$ of 5.95 (table 1). Preliminary tests revealed that a $\mathrm{K}_{2} \mathrm{HPO}_{4} / \mathrm{KH}_{2} \mathrm{PO}_{4}$ ratio (phosphate buffer) of 1:2 was optimal for maintaining a constant $\mathrm{pH}$ (all chemicals were from Merck). Additionally, $0.1 \mathrm{mmol} / \mathrm{l}$ sodium fluoride (Fisher Scientific, Ulm, Germany) was added to the SN. After preparation, modified SN tended to precipitate slightly. Glandosane (carboxymethylcellulose-based; Cell Pharm, Hannover, Germany), representing a demineralising saliva substitute [Joyston-Bechal and Kidd, 1987; Meyer-Lueckel et al., 2002], was tested (table 1). In addition to these 2 saliva substitutes, a non-carbonated mineral water (Volvic; Danone, Frankfurt, Germany) of pH 7.16 was also used.

\section{Specimen Treatment}

After the demineralisation period, half of each demineralised surface was covered with nail varnish (to act as control). The specimens were then randomly divided into 3 groups and stored in either non-carbonated mineral water, Glandosane or SN for 5 weeks $\left(37^{\circ} \mathrm{C}\right)$. Moreover, the specimens were subjected to one of the following treatments twice daily (table 2): no treatment (0); the gentle application of ProSchmelz fluoride gel (PS; GSK, München, Germany) for $10 \mathrm{~min}$; brushing gently for $10 \mathrm{~s}$ with Duraphat (DP; 5,000 $\mu \mathrm{g} \mathrm{F}^{-} / \mathrm{g}$, Colgate-Palmolive, Hamburg, Germany) tooth- 
Table 1. Compositions of the control solution (water) as well as the saliva substitutes and calculated saturations with respect to calcium phosphates and $\mathrm{CaF}_{2}$

\begin{tabular}{|c|c|c|c|c|c|c|c|c|c|c|c|c|c|}
\hline \multirow[t]{2}{*}{ Solution } & \multicolumn{5}{|c|}{$\begin{array}{l}\text { Calculated saturation of an aqueous } \\
\text { solution with respect to }\end{array}$} & \multirow[t]{2}{*}{$\mathrm{pH}$} & \multicolumn{7}{|c|}{ Ion concentrations, $\mathrm{mmol} / \mathrm{l}$} \\
\hline & DCPD & OCP & HA & $\mathrm{CaF}_{2}$ & FA & & $\mathrm{Ca}$ & $\mathrm{PO}_{4}$ & $\mathrm{~F}$ & $\mathrm{~K}$ & $\mathrm{Cl}$ & $\mathrm{Na}$ & $\mathrm{Mg}$ \\
\hline Water (Volvic) & 0.2 & 0.8 & 4.9 & - & - & 7.16 & 0.3 & 0.2 & 0 & 0.2 & 0.4 & 0.5 & 0.3 \\
\hline Glandosane & 0.2 & 0.3 & 1.0 & - & - & 5.35 & 1.0 & 2.6 & 0 & 19.0 & 33.8 & 14.8 & 0.3 \\
\hline Modified SN & 1.3 & 1.9 & 7.1 & 0.6 & 28.5 & 5.95 & 3.2 & 5.0 & 0.1 & 6.7 & 6.3 & 0 & 0 \\
\hline
\end{tabular}

$\mathrm{DCPD}=$ Dicalcuim phosphate dihydrate; $\mathrm{OCP}=$ octacalcium phosphate $\mathrm{HA}=$ hydroxyapatite $\mathrm{CaF}_{2}=$ calcium fluoride; $\mathrm{FA}=$ fluoroapatite.

Table 2. Fluoride agents and their treatment regimes

\begin{tabular}{|c|c|c|c|c|}
\hline Agents & Code & $\begin{array}{l}\text { Concentration } \\
\mu \mathrm{g} \mathrm{F}^{-} / \mathrm{g}\end{array}$ & $\mathrm{pH}$ & Treatment \\
\hline None & 0 & - & - & no treatment \\
\hline ProSchmelz fluoride gel ${ }^{1}$ & PS & 12,500 & 6.03 & $\begin{array}{l}\text { contact with the gel for } 10 \mathrm{~min} \text { in the morning and } \\
\text { evening }\end{array}$ \\
\hline Duraphat toothpaste & $\mathrm{DP}$ & 5,000 & $\begin{array}{l}\text { DP/water }(1: 3)-8.15 \\
\text { DP/G }(1: 3)-7.54 \\
\text { DP/SN }(1: 3)-7.61\end{array}$ & $\begin{array}{l}\text { slurry (ratio } 1: 3 \text { ) from toothpaste with the respective } \\
\text { storage solution and brushing for } 10 \mathrm{~s} \text { with a total } \\
\text { contact time of } 130 \mathrm{~s}\end{array}$ \\
\hline $\begin{array}{l}\text { Duraphat toothpaste } \\
+ \\
\text { ProSchmelz fluoride gel }\end{array}$ & $\mathrm{DP}+\mathrm{PS}$ & see DP and PS & see DP and PS & $\begin{array}{l}\text { same as group DP and additional contact with the } \\
\text { gel for } 10 \mathrm{~min} \text { in the morning and evening after the } \\
\text { toothpaste procedure }\end{array}$ \\
\hline
\end{tabular}

After each treatment, the specimens were washed for $20 \mathrm{~s}$ with approximately $20 \mathrm{ml}$ deionized water ( $\mathrm{n}=11-13 / \mathrm{subgroup}$ ). Duraphat toothpaste was diluted 1:3 with storage solution to obtain a homogeneous slurry (EN ISO 11609), and the specimens were brushed gently with an electric toothbrush (Oral-B Professional Care 7500 with brush head Oral-B Flexisoft). $\mathrm{G}=\mathrm{Glandosane}$.

${ }^{1}$ Contains $0.256 \mathrm{~mol} / \mathrm{l}$ phosphate, as analysed in a previous study [Meyer-Lueckel and Tschoppe, 2010].

paste/storage solution slurry, with an additional contact time of $120 \mathrm{~s}$ with the slurry (total contact time, $130 \mathrm{~s}$ ), or a combination of treatments DP and PS (DP+PS). After 2 weeks, half of the exposed surfaces were nail varnished (effect after 2 weeks). Every second day, the solutions of each group were replenished $(24 \mathrm{ml}$ each time, $37^{\circ} \mathrm{C}$ ), and the $\mathrm{pH}$ values of the storage solutions were checked. The $\mathrm{pH}$ values remained stable during the entire experimental period of 5 weeks.

\section{Transversal Microradiography}

After in vitro exposure, thin sections $(100 \mu \mathrm{m})$ were prepared, and contact microradiographs of the enamel specimens were obtained by transversal microradiography, which were then analysed using special software (transversal microradiography for Windows 2.0.27.2; Inspektor Research System BV, Amsterdam, the Netherlands). For full details, see Meyer-Lueckel et al. [2010]. The investigator was blind with respect to the group allocation.
Mineral density profiles were evaluated from which integrated mineral loss $(\Delta \mathrm{Z})$ and lesion depth $(\mathrm{LD})$ values were calculated following initial demineralisation $\left(\Delta \mathrm{Z}_{\text {Demin }}, \mathrm{LD}_{\text {Demin }}\right)$ and after exposure to the various test solutions for either $2\left(\Delta Z_{\mathrm{Effect} 2}\right.$,

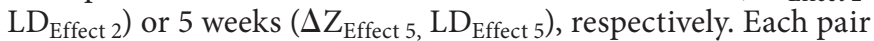
of values was corrected by subtracting the respective values for sound enamel $\left(\Delta \mathrm{Z}_{\text {Sound }}\right.$ and $\left.\mathrm{LD}_{\text {Sound }}\right)$ before data analysis. Changes in mineral loss $\left(\Delta \Delta \mathrm{Z}_{2}=\Delta \mathrm{Z}_{\text {Demin }}-\Delta \mathrm{Z}_{\text {Effect } 2,}, \Delta \mathrm{Z}_{5}=\right.$ $\left.\Delta \mathrm{Z}_{\text {Demin }}-\Delta \mathrm{Z}_{\text {Effect 5 }}\right)$ and in LD $\left(\Delta \mathrm{LD}_{2}=\mathrm{LD}_{\text {Demin }}-\mathrm{LD}_{\text {Effect 2 }}\right.$, $\Delta \mathrm{LD}_{5}=\mathrm{LD}_{\text {Demin }}-\mathrm{LD}_{\text {Effect }}$ ) were analysed for treatment differences. Positive and negative values of $\Delta \Delta \mathrm{Z}$ or $\Delta \mathrm{LD}$ indicated net remineralisation and net demineralisation, respectively.

\section{Statistical Analyses}

Statistical analyses were performed using a statistical software package (PASW for Windows, version 18.0; SPSS, Munich, Germany). Data were tested for normal distribution (Kolmogorov- 


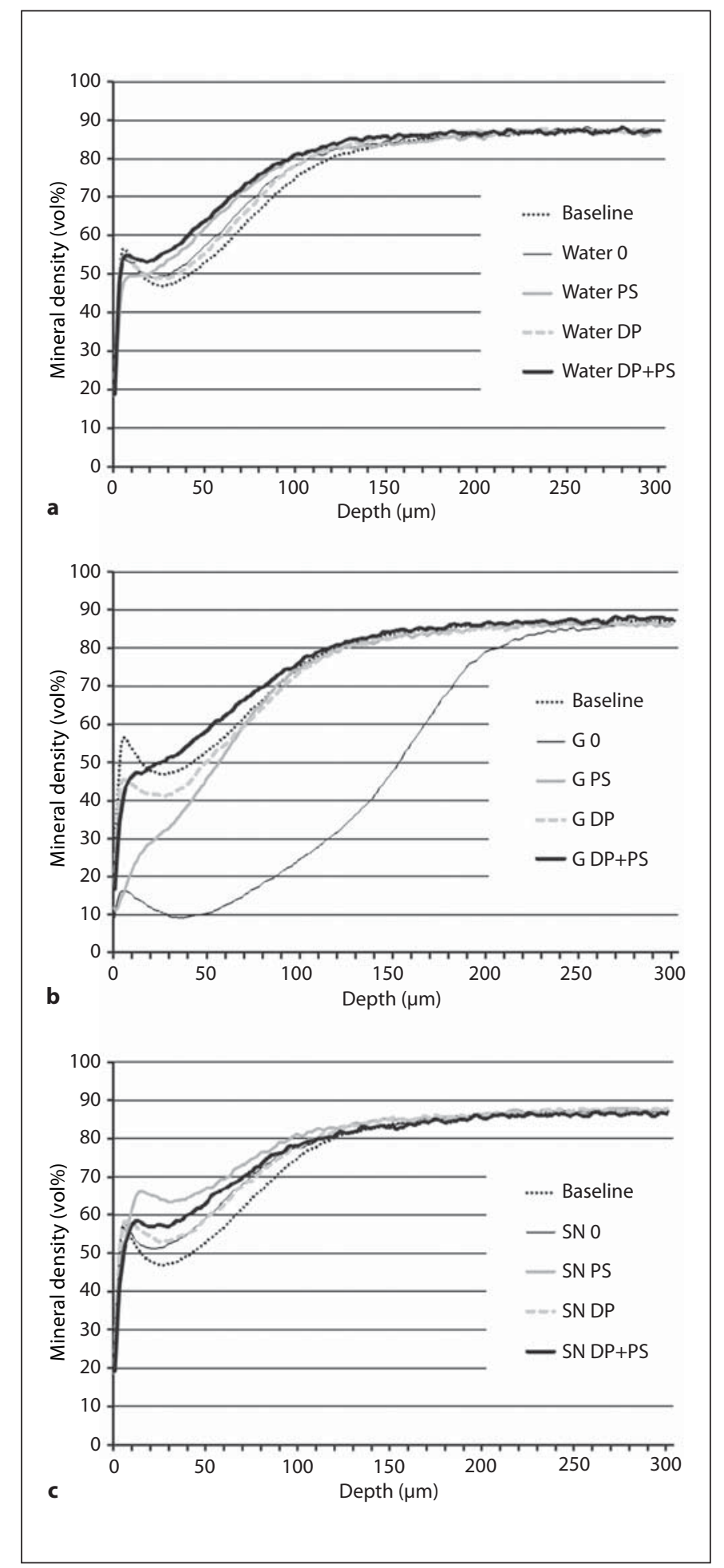

Fig. 1. Mean mineral density profiles of the enamel specimens after 5 weeks of storage in water (a), Glandosane (G; b) and modified $\mathrm{SN}$ (c) with or without additional treatment with fluoride agents compared to baseline. For each storage solution the respective subgroups are depicted: no treatment (0), PS fluoride gel, DP toothpaste, combination $\mathrm{DP}+\mathrm{PS}$.
Smirnov test). $\Delta \Delta \mathrm{Z}$ and $\Delta \mathrm{LD}$ were analysed with regard to the variables 'solution' and 'treatment' using two-way ANOVA. Oneway ANOVA was applied to test for significant differences of $\Delta \Delta \mathrm{Z}$ and $\Delta \mathrm{LD}$ between the groups. Analysis of variance was followed by a Tukey post hoc test. Differences in mineral loss and LD before and after storage/treatment were compared by the paired $t$ test with the level of significance set at $5 \%$.

\section{Results}

All the in vitro demineralised specimens developed subsurface lesions, consistently revealing a surface layer that was more mineralised than the body of the lesion with no signs of erosive loss. $\Delta \mathrm{Z}$ as well as LD did not differ significantly between the various groups at baseline $(\mathrm{p}=0.421$ and $\mathrm{p}=0.175$, respectively; ANOVA). Two specimens were lost during preparation resulting in 11 specimens/group for SN-DP and 13 specimens for all other groups. Mineral losses $\left(\Delta \mathrm{Z}_{\text {Effect 5, }} \Delta \mathrm{Z}_{\text {Effect 2 }}\right)$ and lesion


'solution' and 'treatment' ( $\mathrm{p}<0.006$, two-way ANOVA). Furthermore, significant interaction could be observed among these factors for $\Delta \mathrm{Z}_{\text {Effect } 5,} \Delta \mathrm{Z}_{\text {Effect } 2}$ and $\mathrm{LD}_{\text {Effect } 5}$ $(\mathrm{p}<0.001)$ but not for $\mathrm{LD}_{\text {Effect } 2}(\mathrm{p}=0.575)$.

Storage in Glandosane, either without further treatment or in combination with PS, resulted in pronounced erosion of the surface layer. For Glandosane-PS and Glandosane-DP, inhibition of demineralisation of deeper lesion parts could be observed. Specimens stored in Glandosane and additionally treated with DP+PS revealed nearly complete inhibition of demineralisation of the surface layer; for deeper lesion parts, a tendency towards remineralisation could be seen. Specimens of all other groups revealed subsurface lesions without erosive or abrasive loss after storage (fig. 1).

In vitro exposure for either 2 or 5 weeks to Glandosane alone resulted in significantly lower $\Delta \Delta Z_{\text {Effect 2, }}$, $\Delta \Delta \mathrm{Z}_{\text {Effect } 5}$ and $\Delta \mathrm{LD}_{\text {Effect } 5}$ values compared to those for all other solutions ( $\mathrm{p}<0.05$; ANOVA, Tukey). $\Delta \mathrm{LD}_{\text {Effect } 2}$ values of specimens stored in Glandosane were significantly lower compared to those for water-PS, water-DP and water-DP+PS $(\mathrm{p}<0.05)$ but revealed no significant differences compared to the other groups $(p>0.05)$. No significant differences with regard to $\Delta \Delta \mathrm{Z}_{\text {Effect 2, }}$ $\Delta \Delta \mathrm{Z}_{\text {Effect } 5}, \Delta \mathrm{LD}_{\text {Effect } 2}$ and $\Delta \mathrm{LD}_{\text {Effect } 5}$ values could be observed between only storage and storage plus any of the treatments for water and SN ( $p>0.05$; fig. 2).

Remineralisation (all outcomes, i.e. decreased $\Delta \mathrm{Z}$ and LD) could be observed for water in combination with all fluoride treatments after both periods $(\mathrm{p}<0.05$; paired 
t test). After 2 as well as 5 weeks of exposure, significantly increased (demineralisation) $\Delta \mathrm{Z}\left(\Delta \mathrm{Z}_{\mathrm{Effect} 2}\right.$ and $\left.\Delta \mathrm{Z}_{\text {Effect } 5}\right)$ as well as $\mathrm{LD}\left(\mathrm{LD}_{\text {Effect } 2}\right.$ and $\left.\mathrm{LD}_{\text {Effect } 5}\right)$ compared with baseline could be observed for Glandosane alone ( $\mathrm{p}<$ 0.05; paired t test). Specimens of SN-0 and SN-PS showed significantly decreased $\Delta Z_{\text {Effect } 5}$ values compared with baseline $(\mathrm{p}<0.001)$. For SN-DP, this was the case for $\Delta \mathrm{Z}_{\text {Effect } 2}, \Delta \mathrm{Z}_{\text {Effect } 5}$ and $\mathrm{LD}_{\text {Effect } 5}$ (tables 3, 4).

\section{Discussion}

This in vitro study demonstrated mainly that both fluoride gel (PS) and fluoride toothpaste (DP) reduce the detrimental demineralising effect of Glandosane observed previously [Joyston-Bechal and Kidd, 1987; Smith et al., 2001; Meyer-Lueckel et al., 2002]. The modified (with respect to the saturation of calcium phosphates) SN alone and in combination with the fluoride gel or toothpaste results in remineralising effects after 5 weeks. Therefore, the first hypothesis (that the additional use of fluoride results in less pronounced demineralisation when the specimens are stored in Glandosane) could not be rejected, whereas the second hypothesis (that the additional use of fluoride results in enhanced remineralisation when modified $\mathrm{SN}$ is used) could be rejected.

In the present study, the demineralised specimens (subsurface lesions) were stored daily for a period of 5 weeks in the different solutions. This can be considered as an extremely long contact time with artificial saliva. However, it is important to consider that patients suffering from hyposalivation generally use saliva substitutes or non-carbonated water ad libitum [Atkinson et al., 2005; Kielbassa et al., 2006]. Thus, similar effects might be conceivable after longer in vivo periods. No pH cycling model was chosen to evaluate the potential remineralising effects of the fluoride agents more efficiently. However, this should be taken into account when interpreting the data.

For patients who are currently undergoing or have undergone radiation therapy in the past, brushing with a highly concentrated fluoride toothpaste and the application of a fluoride gel using a customised mouth tray are recommended more frequently compared to the regimes recommended for persons with normal salivary flow rates [Wei and Yiu, 1993]. Mimicking this scenario, each specimen was either brushed with a paste/saliva substitute slurry or a paste/water slurry for $10 \mathrm{~s}$ twice daily (total contact time, $130 \mathrm{~s}$ ), or the gel was applied gently to the top surface of each specimen for 10 min twice daily.

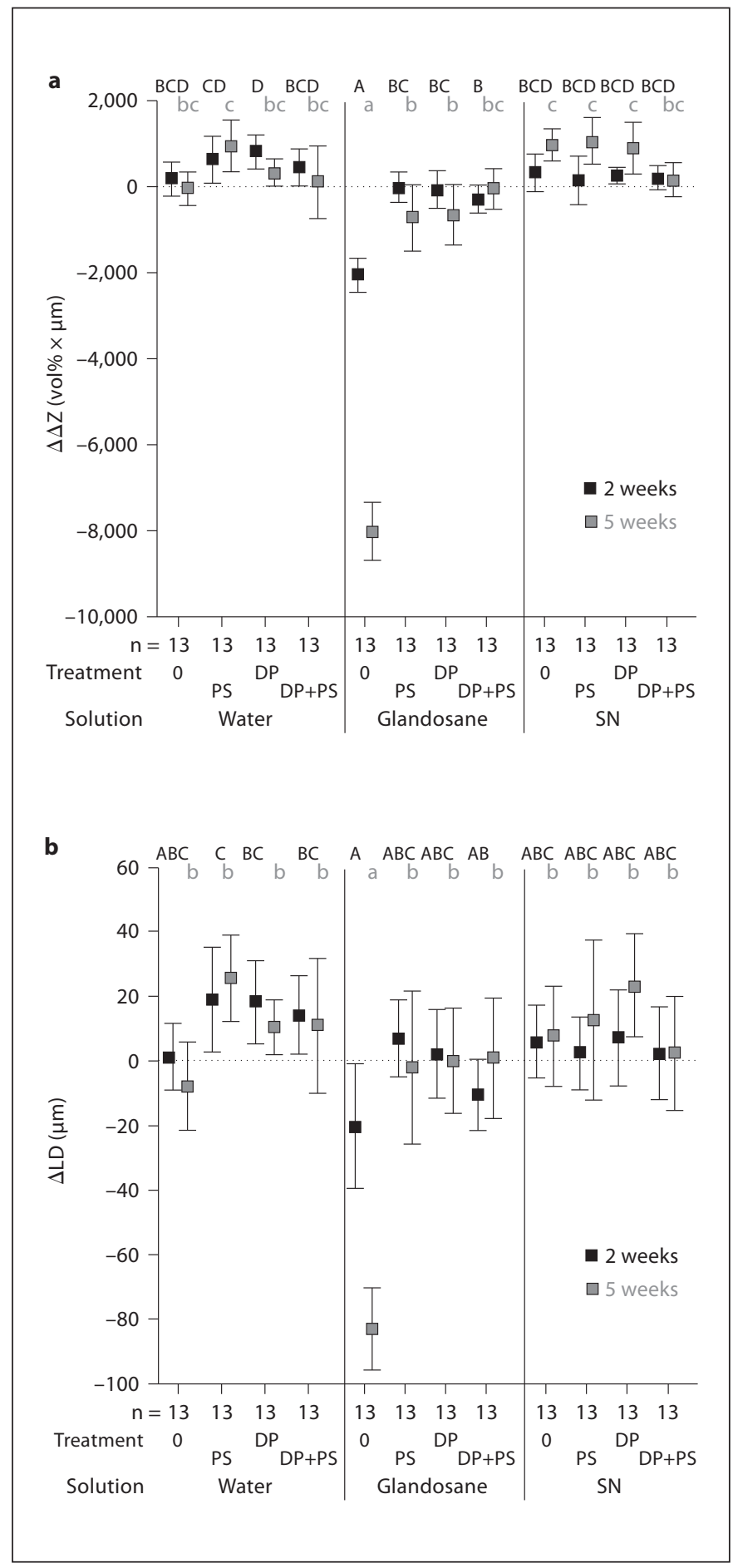

Fig. 2. Means and 95\% confidence intervals of the differences in mineral change (a) and LD (b) after 2 and 5 weeks storage in the various solutions (water, Glandosane and modified SN). Within each main group (solution), specimens were additionally treated as follows: no treatment (0), PS fluoride gel, DP toothpaste, combination DP+PS. Different letters at the top indicate significant differences between the subgroups within each storage period $(\mathrm{p}<0.05$; ANOVA, Tukey post hoc test). 
Table 3. Means and standard deviations of the mineral losses $(\Delta \mathrm{Z}$; vol\% $\times \mu \mathrm{m})$ after in vitro demineralisation $\left(\Delta \mathrm{Z}_{\mathrm{Demin}}\right)$ and storage

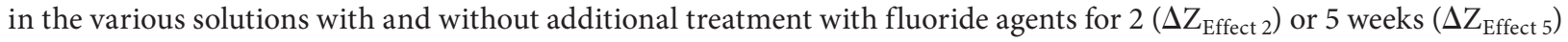

\begin{tabular}{|c|c|c|c|c|c|c|c|c|c|}
\hline \multirow[t]{2}{*}{ Solution } & \multirow[t]{2}{*}{ Treatment } & \multicolumn{2}{|c|}{$\Delta \mathrm{Z}_{\text {Demin }}$} & \multicolumn{2}{|c|}{$\Delta Z_{\text {Effect } 2}$} & \multirow{2}{*}{$\begin{array}{l}\text { Demin-Effect } 2 \\
\mathrm{p}\end{array}$} & \multicolumn{2}{|c|}{$\Delta \mathrm{Z}_{\text {Effect } 5}$} & \multirow{2}{*}{$\begin{array}{l}\text { Demin-Effect } 5 \\
\mathrm{p}\end{array}$} \\
\hline & & mean & SD & mean & SD & & mean & SD & \\
\hline \multirow[t]{4}{*}{ Water } & 0 & 2,824 & 806 & 2,633 & 864 & 0.319 & 2,846 & 874 & 0.907 \\
\hline & PS & 3,224 & 1,127 & 2,582 & 825 & 0.024 & 2,280 & 949 & 0.005 \\
\hline & $\mathrm{DP}$ & 3,250 & 932 & 2,419 & 638 & 0.001 & 2,917 & 962 & 0.045 \\
\hline & $\mathrm{DP}+\mathrm{PS}$ & 2,561 & 510 & 2,012 & 734 & 0.002 & 2,020 & 991 & 0.008 \\
\hline \multirow[t]{4}{*}{ Glandosane } & 0 & 2,853 & 861 & 4,933 & 659 & $<0.001$ & 10,868 & 1,536 & $<0.001$ \\
\hline & PS & 3,284 & 646 & 3,326 & 853 & 0.801 & 4,028 & 1,176 & 0.056 \\
\hline & $\mathrm{DP}$ & 2,930 & 1,176 & 3,009 & 861 & 0.689 & 3,605 & 1,236 & 0.051 \\
\hline & $\mathrm{DP}+\mathrm{PS}$ & 2,935 & 1,235 & 3,247 & 1,330 & 0.057 & 2,997 & 1,397 & 0.773 \\
\hline \multirow[t]{4}{*}{ Modified SN } & 0 & 3,464 & 835 & 3,158 & 649 & 0.148 & 2,495 & 911 & $<0.001$ \\
\hline & PS & 2,992 & 969 & 2,862 & 1,320 & 0.616 & 1,954 & 597 & 0.002 \\
\hline & $\mathrm{DP}$ & 3,158 & 1,224 & 2,898 & 1,233 & 0.010 & 2,275 & 925 & 0.007 \\
\hline & $\mathrm{DP}+\mathrm{PS}$ & 2,678 & 775 & 2,497 & 704 & 0.202 & 2,535 & 703 & 0.448 \\
\hline
\end{tabular}

$\mathrm{p}$ values of differences between the values after demineralisation and storage/treatment for either 2 (Demin-Effect 2 ) or 5 weeks (Demin-Effect 5) within each group ( $n=11$ in group SN-DP and $n=13$ in all other groups) as analysed by $t$ tests. $p$ values of pairs differing significantly are italicised.

Table 4. Means and standard deviations of the $\mathrm{LD}(\mu \mathrm{m})$ after in vitro demineralisation $\left(\mathrm{LD}_{\text {Demin }}\right)$ and storage in the various solutions with and without additional treatment with fluoride agents for $2\left(\mathrm{LD}_{\text {Effect } 2}\right)$ as well as 5 weeks $\left(\mathrm{LD}_{\text {Effect 5 }}\right)$

\begin{tabular}{|c|c|c|c|c|c|c|c|c|c|}
\hline \multirow[t]{2}{*}{ Solution } & \multirow[t]{2}{*}{ Treatment } & \multicolumn{2}{|c|}{$\mathrm{LD}_{\text {Demin }}$} & \multicolumn{2}{|c|}{ LD $_{\text {Effect } 2}$} & \multirow{2}{*}{$\begin{array}{l}\text { Demin-Effect } 2 \\
\mathrm{p}\end{array}$} & \multicolumn{2}{|c|}{$\mathrm{LD}_{\text {Effect } 5}$} & \multirow{2}{*}{$\begin{array}{l}\text { Demin-Effect } 5 \\
\mathrm{p}\end{array}$} \\
\hline & & mean & $\mathrm{SD}$ & mean & $\mathrm{SD}$ & & mean & SD & \\
\hline \multirow[t]{4}{*}{ Water } & 0 & 102 & 22 & 101 & 23 & 0.810 & 110 & 20 & 0.224 \\
\hline & PS & 118 & 25 & 99 & 28 & 0.027 & 92 & 32 & 0.001 \\
\hline & $\mathrm{DP}$ & 113 & 24 & 94 & 16 & 0.009 & 102 & 19 & 0.020 \\
\hline & $\mathrm{DP}+\mathrm{PS}$ & 100 & 25 & 85 & 19 & 0.048 & 83 & 27 & 0.043 \\
\hline \multirow[t]{4}{*}{ Glandosane } & 0 & 106 & 21 & 126 & 22 & 0.041 & 189 & 21 & $<0.001$ \\
\hline & PS & 120 & 18 & 113 & 27 & 0.220 & 122 & 35 & 0.851 \\
\hline & $\mathrm{DP}$ & 118 & 29 & 116 & 17 & 0.756 & 118 & 26 & 0.998 \\
\hline & $\mathrm{DP}+\mathrm{PS}$ & 112 & 22 & 123 & 19 & 0.057 & 111 & 32 & 0.915 \\
\hline \multirow[t]{4}{*}{ Modified SN } & 0 & 121 & 17 & 115 & 13 & 0.265 & 113 & 26 & 0.305 \\
\hline & PS & 111 & 25 & 109 & 27 & 0.637 & 99 & 28 & 0.287 \\
\hline & $\mathrm{DP}$ & 122 & 23 & 114 & 37 & 0.311 & 98 & 26 & 0.008 \\
\hline & $\mathrm{DP}+\mathrm{PS}$ & 121 & 28 & 119 & 21 & 0.747 & 118 & 22 & 0.760 \\
\hline
\end{tabular}

$\mathrm{p}$ values of differences between the values after demineralisation and storage/treatment for either 2 (Demin-Effect 2 ) or 5 weeks (Demin-Effect 5) within each group $(\mathrm{n}=11$ in group SN-DP and $\mathrm{n}=13$ in all other groups) as analysed by tests are given. $\mathrm{p}$ values of pairs differing significantly are italicised. 
Although not standardised (i.e. by using a brushing machine), the chosen brushing procedure by itself should not have influenced the results (i.e. the group comparison) because a variable toothbrush pressure should have averaged out over time. Furthermore, the evaluation of the surface during the transversal microradiography assessment indicated no visible abrasion of the surface arising from the brushing procedure.

Saliva substitutes for patients with diminished saliva production have been developed primarily to alleviate the symptoms experienced during mastication, swallowing and speech [Atkinson et al., 2005]. With reference to these parameters, saliva substitutes have been shown to provide relief in cases of radiogenic hyposalivation and elsewhere [Nieuw Amerongen and Veerman, 2003]. However, patients with hyposalivation often alleviate their oral symptoms by drinking water because it is convenient and cheap. For this reason, a fluoride-free, non-carbonated mineral water was used in this study as a control. After both storage periods in water, no changes in mineralisation were observed, which might be explained by the calculated saturations with respect to the relevant calcium phosphates $\left(\mathrm{S}_{\mathrm{HA}}\right.$ of $4.9 / \mathrm{S}_{\mathrm{OCP}}$ of 0.8 ) [Iijima, 2001].

The commercially available saliva substitute Glandosane demonstrated a remarkable demineralising effect in addition to the erosion of the surface. Similar effects on enamel have been observed previously [Joyston-Bechal and Kidd, 1987; Meyer-Lueckel et al., 2002]. This might be explained by the low $\mathrm{pH}$ value; the unspecified amount of titratable acids may have led to low saturation with respect to $\mathrm{HA}\left(\mathrm{S}_{\mathrm{HA}}=1.0\right.$; table 1$)$. In contrast, the modified SN remineralised the specimens, and this might be explained by the supersaturation with respect to HA, OCP and DCPD [Tschoppe et al., 2009b].

Two different fluoride-containing agents were used in this study: a fluoride gel $\left(12,500 \mu \mathrm{g} \mathrm{F}^{-} / \mathrm{g}\right)$ and a highly concentrated fluoride toothpaste $(5,000 \mu \mathrm{g} \mathrm{F} / \mathrm{g})$. All fluoride treatments were capable of preventing further demineralisation of the specimens stored in Glandosane. As a result of these fluoride treatments, a distinct calcium-fluoride-like layer on the specimen surfaces may have been established [Christoffersen et al., 1988; Ogaard, 2001], which appeared to be dissolved over time by Glandosane. Contact of the specimens with the neutral mineral water $\left(\mathrm{S}_{\mathrm{HA}}\right.$ of 4.9$)$ should not have affected the layer mentioned above. Consequently, available fluorides in the layer were capable of remineralising the specimens [Ogaard, 2001], resulting in a more pronounced remineralisation compared to that associated with the use of mineral water alone.

Effect of Fluoride Agents on Enamel Subsurface Lesions
PS fluoride gel, containing considerable amounts of phosphate [Meyer-Lueckel and Tschoppe, 2010], demonstrated statistically significant remineralising effects when used in combination with SN and water without inducing erosion. Similar results have been observed in previous studies, in which even acidic fluoride gels have been shown to be effective in the prevention of erosion [Lagerweij et al., 2006]. One possible cause might be the $\mathrm{pH}$ value of PS, which was above the critical $\mathrm{pH}$ for enamel demineralisation [Featherstone, 2004]. The increased phosphate concentration may have also influenced the mineralisation process. If phosphate is present during formation of the calcium fluoride layer, it will be incorporated into the lattice structure. This 'phosphate-contaminated calcium fluoride' is understood to be more soluble than pure calcium fluoride [Christoffersen et al., 1988], leading to an enhanced transformation of this layer to fluoroapatite [Chander et al., 1982]. Consequently, the remineralisation of the deeper parts of the lesions and the surface could be observed when PS was used in combination with water or SN.

The application of DP toothpaste resulted in a remineralising effect when combined with SN or water. For both solutions, this may have been accomplished by the creation of a calcium-fluoride-like layer on the specimen surface. The brushing procedure with the slurry might have induced a slight abrasion on the outermost surface, resulting in a 'calcium-enriched slurry'. Because of the higher concentration of available fluoride when using DP compared with storage in water or $\mathrm{SN}$ alone, the formation of a calcium-fluoride-like layer was probably enhanced [Christoffersen et al., 1988; Cruz et al., 1992; Ogaard, 2001]. Thus, a remineralising effect was induced when using DP in combination with water. However, the remineralising effects observed when using $\mathrm{SN}$ alone were not enhanced.

SN was modified with fluoride, calcium and phosphate resulting in a solution that was supersaturated with respect to relevant calcium phosphates and calcium fluoride [Tschoppe et al., 2009b]. Given that SN contains $2 \mu \mathrm{g}$ $\mathrm{F}^{-} / \mathrm{g}$, it is no surprise that a precipitate was seen in the $\mathrm{SN}$ solution. Presumably this precipitate was fluoride-substituted apatite, though other phases are possible (e.g. dicalcium phosphate dihydrate). Hence, the remineralisation potential of the modified SN was slightly decreased. On preparing the slurry (by mixing $\mathrm{SN}$ with the fluoride toothpaste), the degree of saturation would have been increased even more and calcium-fluoride-like precipitates in the DP/SN slurry should have been favoured [Larsen and Jensen, 1994]. Such precipitates, together with the 
calcium-fluoride-like layer mentioned above, could have caused surface blocking leading to reduced ion transport into deeper parts of the artificial lesions. Therefore, remineralisation induced by $\mathrm{SN}$ alone could not be enhanced using DP toothpaste. The combination of $\mathrm{SN}-\mathrm{DP}+\mathrm{PS}$ resulted in no significant remineralisation. Most likely, the calcium fluoride layer that we postulated to develop after brushing was enhanced by application of the fluoride gel, leading to a highly mineralised surface layer that blocked ion diffusion into deeper parts of the lesion during the subsequent storage in SN [Preston et al., 2008].

In patients with hyposalivation arising from irradiation in the head and neck area, long-term compliance with a 2-step regime is quite poor [Horiot et al., 1983; Epstein et al., 1996]. Therefore, the use of a remineralising saliva substitute alone could be a promising approach for dentate patients with hyposalivation to manage both outcomes (dental caries and hyposalivation). According to the present results and using a 'remineralisation model', the modified SN, being supersaturated with respect to the relevant calcium phosphates, appears to have this potential. Within the limitations of this in vitro study, it can be concluded that the use of fluoride agents (i.e. a fluoride gel or highly concentrated fluoride toothpaste) reduces the detrimental effects of demineralising saliva substitutes, but it cannot enhance the remineralising effects of a remineralising artificial saliva.

\section{Acknowledgements}

This study was supported by the Deutsche Krebshilfe e.V. (grant 70-3117-Me-1).

\section{Disclosure Statement}

The authors declare no conflict of interest.

\section{References}

-Atkinson JC, Grisius M, Massey W: Salivary hypofunction and xerostomia: diagnosis and treatment. Dent Clin North Am 2005;49: 309-326.

Chander S, Chiao CC, Fuerstenau DW: Transformation of calcium fluoride for caries prevention. J Dent Res 1982;61:403-407.

Christoffersen J, Christoffersen MR, Kibalczyc W, Perdok WG: Kinetics of dissolution and growth of calcium fluoride and effects of phosphate. Acta Odontol Scand 1988;46: 325-336.

Cruz R, Ogaard B, Rolla G: Uptake of KOH-soluble and $\mathrm{KOH}$-insoluble fluoride in sound human enamel after topical application of a fluoride varnish (Duraphat) or a neutral 2\% NaF solution in vitro. Scand J Dent Res 1992; 100:154-158.

Epstein JB, van der Meij EH, Lunn R, StevensonMoore P: Effects of compliance with fluoride gel application on caries and caries risk in patients after radiation therapy for head and neck cancer. Oral Surg Oral Med Oral Pathol Oral Radiol Endod 1996;82:268-275.

Featherstone JD: The continuum of dental caries - evidence for a dynamic disease process. J Dent Res 2004;83(spec No C):39-42.

-Horiot JC, Schraub S, Bone MC, Bain Y, Ramadier J, Chaplain G, Nabid N, Thevenot B, Bransfield D: Dental preservation in patients irradiated for head and neck tumours: a 10year experience with topical fluoride and a randomized trial between two fluoridation methods. Radiother Oncol 1983;1:77-82.
Iijima M: Formation of octacalcium phosphate in vitro; in Chow LC, Eanes ED (eds): Octacalciumphosphate. Monogr Oral Sci. Basel, Karger, 2001, vol 18, pp 17-49.

Joyston-Bechal S, Kidd EA: The effect of three commercially available saliva substitutes on enamel in vitro. Br Dent J 1987;163:187-190.

Kielbassa AM, Hinkelbein W, Hellwig E, MeyerLueckel H: Radiation-related damage to dentition. Lancet Oncol 2006;7:326-335.

Lagerweij MD, Buchalla W, Kohnke S, Becker K, Lennon AM, Attin T: Prevention of erosion and abrasion by a high fluoride concentration gel applied at high frequencies. Caries Res 2006;40:148-153.

Larsen MJ, Jensen SJ: Experiments on the initiation of calcium fluoride formation with reference to the solubility of dental enamel and brushite. Arch Oral Biol 1994;39:23-27.

Lynch E, Baysan A: Reversal of primary root caries using a dentifrice with a high fluoride content. Caries Res 2001;35:60-64.

Meyer-Lueckel H, Colfen H, Verch A, Tschoppe P: Effects of carboxymethylcellulose-based saliva substitutes with varying degrees of saturation with respect to calcium phosphates on artificial enamel lesions. Caries Res 2010;44:127-134.

-Meyer-Lueckel H, Schulte-Monting J, Kielbassa AM: The effect of commercially available saliva substitutes on predemineralized bovine dentin in vitro. Oral Dis 2002;8:192-198

Meyer-Lueckel H, Tschoppe P: Effect of fluoride gels and mouthrinses in combination with saliva substitutes on demineralized bovine enamel in vitro. J Dent 2010;38:641-647.
-Nieuw Amerongen AV, Veerman EC: Current therapies for xerostomia and salivary gland hypofunction associated with cancer therapies. Support Care Cancer 2003;11:226-231.

Ogaard B: $\mathrm{CaF}_{2}$ formation: cariostatic properties and factors of enhancing the effect. Caries Res 2001;35:40-44.

Preston KP, Smith PW, Higham SM: The influence of varying fluoride concentrations on in vitro remineralisation of artificial dentinal lesions with differing lesion morphologies. Arch Oral Biol 2008;53:20-26.

Shellis RP: A microcomputer program to evaluate the saturation of complex solutions with respect to biominerals. Comput Appl Biosci 1988;4:373-379.

Smith G, Smith AJ, Shaw L, Shaw MJ: Artificial saliva substitutes and mineral dissolution. J Oral Rehabil 2001;28:728-731.

Tschoppe P, Kielbassa AM, Meyer-Lueckel H: Evaluation of the remineralising capacities of modified saliva substitutes in vitro. Arch Oral Biol 2009a;54:810-816.

Tschoppe P, Kielbassa AM, Toll R, Meyer-Lueckel H: Modification of the mineralizing capacity of a saliva substitute (Saliva natura) on enamel in vitro (in German). Laryngorhinootologie 2009b;88:717-722.

-Vissink A, Burlage FR, Spijkervet FK, Jansma J, Coppes RP: Prevention and treatment of the consequences of head and neck radiotherapy. Crit Rev Oral Biol Med 2003;14:213-225.

Wei SH, Yiu CK: Evaluation of the use of topical fluoride gel. Caries Res 1993;27:29-34. 